\title{
Consumer acceptance of novel food technologies
}

\author{
Michael Siegrist $₫$ and Christina Hartmann ${ }^{\bowtie}$
}

\begin{abstract}
Novel food technologies are important for food security, safety and sustainability. Consumers, however, are often hesitant to accept them. In this narrative Review, we organize the research describing how heuristics and individual differences among consumers influence the acceptance of agri-food technologies. Associations evoked by a food technology, its perceived naturalness and trust in the industry using it influence consumer acceptance. Food neophobia, disgust sensitivity and cultural values are crucial personality factors for explaining individual differences. Using gene technology, nanotechnology, cultured meat and food irradiation as cases, we explore factors that may explain consumers' acceptance or lack of acceptance. Climate change, food supply shocks caused by crises such as pandemics and population growth are imminent threats to the food system. Therefore, disruptive food technologies will be needed to progress towards a more resilient food system. Taking into account the factors influencing consumers' perceptions of novel food technologies during the early stage of development and introduction will hopefully result in a higher acceptance of such technologies.
\end{abstract}

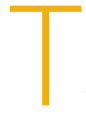
echnologies employed along the supply chain have enhanced the safety, nutritional value and sustainability of food, and yet agri-food technologies are not always perceived in a positive way by consumers ${ }^{1-3}$. As we look to 'disruptive technologies' for transforming food systems, important questions arise: Why do consumers reject food technologies that experts perceive safe? What factors influence consumers' perceptions and acceptance of novel food technologies? Consumers will have a fundamental influence on what technologies in agriculture and food production are implemented and successful on the market. Many consumers perceive the use of food technologies as contradictory to healthy, nutritious, tasty food, which may be a challenge for the food industry. It is crucial to take consumers' views into account during the early stages of product development.

Here, we review the literature on consumer perceptions of novel food technologies related to the production, preparation and storage of food (that is, gene technology (GT), nanotechnology, cultured meat and food irradiation). The term 'novel' does not necessarily refer to the invention of a technology, but rather to its introduction into the market. For example, even though food irradiation was invented in the previous century, we consider it as a novel technology because in some countries it has only been introduced recently and irradiated foods are accepted in some countries but not in others. We do not review how experts evaluate agricultural and food technologies, but solely on the factors that shape consumers' attitudes toward and acceptance of such technologies. Consumers often rely on simple cues or heuristics, such as their perceived naturalness of food technologies or feelings of disgust evoked by the unfamiliar, as well as trust in the food industry, because they lack the technological knowledge. Several personality factors, including food technology neophobia or food disgust sensitivity, explain individual differences in people's attitudes toward food technologies. For selected food technologies, we explain the most important factors that influence consumer acceptance.

\section{Perception of food technologies}

The food domain has witnessed technological progress; Fig. 1 overviews the timeline for invention or introduction of selected significant innovations in the agri-food domain ${ }^{4,5}$. Unlike in other domains, technological development in food has little obsolescence over time-new technologies do not replace older ones so much, but build upon and add to. As a consequence, there is much less pressure for consumers to accept innovations compared with other domains.

In many domains, technological progress is perceived positively ${ }^{6}$. The food domain has been shown to be slightly different in this respect. Some novel food technologies (for example, GT) encounter strong resistance by a considerable number of consumers ${ }^{7}$. Regarding food, technological applications are most often viewed as negative attributes, while food naturalness-produced with a minimum of obvious human intervention-is viewed as an inherently positive attribute ${ }^{8}$. The negative image of highly processed food is strongly influenced by a perceived lack of naturalness ${ }^{9}$. Moreover, humans by nature tend to be conservative concerning unfamiliar, novel foods ${ }^{10}$ and thus novel food technologies ${ }^{11}$. How conservative humans can be regarding culturally defined dietary behaviour is emphasized by the fact that even if non-traditional foods become accepted (for example, sushi, plant-based meat substitutes in the US or Europe), this does not fundamentally change people's established diets and might only increase food variety ${ }^{12,13}$.

\section{Role of heuristics}

Consumers tend to have limited nutrition knowledge ${ }^{14}$, incorrect perceptions of the environmental impact of food products ${ }^{15}$ and scarce knowledge about food production ${ }^{16}$. Consequently, laypeople's evaluation of food technologies is often based on heuristic processes, not on elaborate information processing ${ }^{17}$. Undoubtedly, heuristics play an important role in many decision situations ${ }^{18,19}$. When people rely on a heuristic to assess a food hazard, a target attribute (for example, number of fatalities caused by a food hazard) that is not readily accessible is substituted with a heuristic attribute that comes to mind more easily (for example, number of specific events someone suffered from a food hazard $)^{20}$. However, the literature is divided on whether the use of heuristics results in smart or poor decisions. The so-called 'heuristic and bias programme' focuses on the negative side of heuristics ${ }^{19}$. This research tradition has identified a large number of heuristics that may cause both laypeople and experts to make biased decisions ${ }^{21}$. By contrast, 


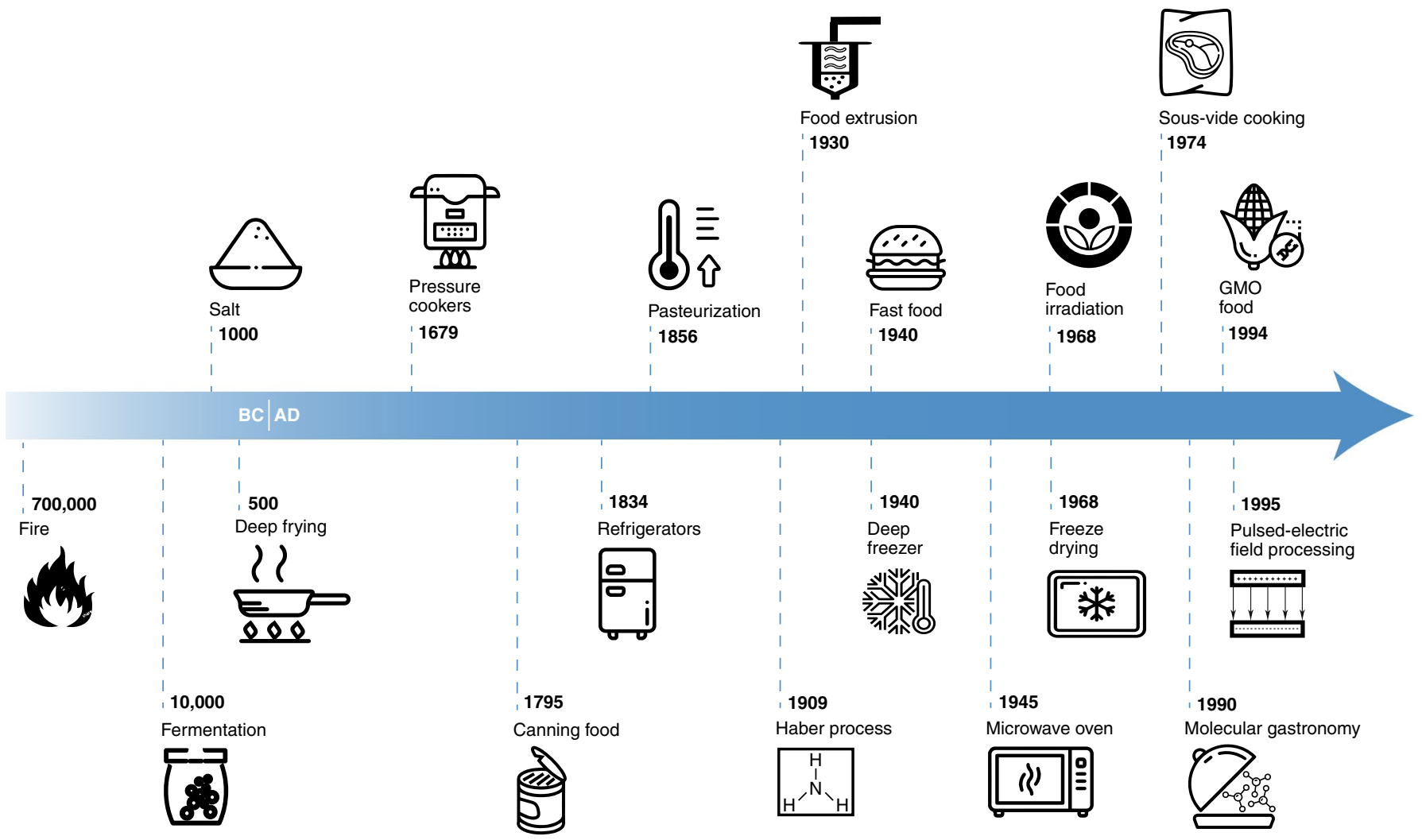

Fig. 1 Historical timeline of food technologies. Some food technologies (for example, GT and food irradiation) encounter strong resistance, whereas others (for example, refrigerators and freeze drying) have been widely accepted. Unlike in other domains, new food technologies do not replace older ones so much. As a result, there is much less pressure to accept innovations. Credit: www.flaticon.com: Freepik (salt, refrigerator, Pasteurization, fast food, microwave, sous vide, molecular gastronomy); Smashicon (deep frying, canned food, molecular gastronomy); Darius Dan (pressure cooker); Photo3ideastudio (GMO food).

research on the positive aspects demonstrates that heuristics can be efficient tools that, if used in the right environment, allow human beings to make sound decisions ${ }^{18,22}$. However, relying on heuristics when evaluating food hazards can result in biased decisions ${ }^{23}$. The same benefit was perceived more positively when it was the result of traditionally bred crops compared with genetically modified (GM) crops, for example ${ }^{23}$.

People utilize a large set of heuristics when making decisions ${ }^{19,21,24}$. In the following subsections, we focus on affect, trust and natural-is-better heuristics, which are most often used to explain consumers' risk perceptions or acceptance of food technologies and food hazards.

Affect heuristic. The affect heuristic proposes that people rely on the affective meaning that they associate with an image or the associations elicited by an object when asked to evaluate its risks or benefits $^{25}$. In the case of GT, some consumers may spontaneously think of 'Frankenstein food', and this perception may evoke strong negative feelings, whereas other consumers may associate GT with 'golden rice'; as a result, their association is positively tagged.

In line with the affect heuristic, emotions have been found to influence people's risk perceptions or risk judgments ${ }^{26,27}$. Hazards associated with stronger feelings of dread are judged to be riskier compared with hazards that do not evoke such feelings ${ }^{27}$. The affect heuristic may therefore explain why laypeople are concerned about some food hazards but not others, as well as why laypeople and experts differ in their risk perceptions. This heuristic has also been used to explain why laypeople differ in their acceptance of the same technology ${ }^{28}$. For example, consumers for whom GT is associated with negative feelings are less willing to purchase GM foods compared with people who associate positive images with this technology ${ }^{29}$. The affect heuristic has also been used to explain the acceptance of food irradiation ${ }^{3}$ or of nanotechnology in foods and food packaging ${ }^{30}$. In contrast with laypeople's risk judgments, those of experts are not influenced by the affect associated with a hazard ${ }^{31}$. Due to their knowledge, experts can rely more on the analytical system for the evaluation of a food technology, but due to laypeople's lack of technical knowledge, they need to rely on their experiential system, which is more driven by affect, concrete images, metaphors or narratives ${ }^{17}$, when assessing risks and benefits of novel food technologies. Most of the studies that have examined the impact of the affect heuristic on the acceptance of a technology have focused on general affect, ranging from negative to positive ${ }^{25}$. A more specific emotion is disgust, which can be viewed as a particular case of the affect heuristic. Evoked disgust has been found to influence the acceptance of $\mathrm{GT}^{32}$ and other novel food technologies ${ }^{33}$.

Trust heuristic. Trust has been described $\mathrm{as}^{34}$, and fulfils the criteria of, a heuristic $\mathrm{c}^{20,30}$. If people rely on trust to evaluate a food technology, they substitute a target attribute (for example, improved yields) with cues that indicate trust in the source of this information (for example, value similarity) ${ }^{35}$. Consumers who buy organic foods cannot tell how these items are produced and whether their premium price is justified ${ }^{36}$. Regarding other credence attributes of products, consumers need to trust that the agents in the food chain honestly label the products and do not take advantage of the existing information asymmetry ${ }^{36}$. Trust is also important in situations where people lack knowledge for assessing a technology's benefits 
and risks and therefore have to rely on others ${ }^{37}$. Society can be characterized by high degrees of division of labour and complexity. The trust heuristic, which implies that people depend on others' performance or assessments, helps them reduce complexity and remain capable of acting in a complex environment ${ }^{38,39}$. Therefore, trust plays an important role in food acceptance, and it has been shown to influence risk and benefit perceptions of novel food technologies $^{40-42}$. Trust also seems to be important in consumers' reacceptance of a product after a crisis situation ${ }^{43}$.

How do people decide whom to trust? Reviews of the trust and risk perception literature suggest that it might be helpful to distinguish between two types of trust, namely social trust and confidence $^{34}$. Social trust is based on perceived value similarities, and people tend to trust institutions with similar values as theirs and to distrust institutions whose values differ from theirs ${ }^{44}$, whereas confidence is based on past experience ${ }^{44}$ or perceived competencies ${ }^{45}$. Consumers may have confidence in the food industry's competencies to produce safe foods or in a food technology, but they may lack social trust in the food industry because they believe that it values profit more than consumers' health. Social trust is therefore more relevant to consumer acceptance than confidence, in that consumers believe that the promised added value in food products (for example, fair trade, organic production, healthiness) is actually delivered. It is not mainly a question of the food industry's ability and competence but whether it is honest in disclosing benefits that cannot be directly judged by consumers ${ }^{46}$.

Natural-is-better heuristic. Natural evokes almost exclusively positive emotions in Western countries ${ }^{47}$. As a consequence, for the majority of consumers, naturalness in foods is of high importance, and natural foods are automatically perceived as healthier and tastier, as well as better for the environment ${ }^{9}$. The absence of human processing is a key feature of perceived naturalness ${ }^{8,47}$. However, the type of processing determines how strongly it influences perceived naturalness. Chemical changes reduce perceived naturalness more than physical transformations ${ }^{8,48}$. Furthermore, the process (for example, minerals added to spring water versus minerals naturally in the spring water) seems to be more important than the content (for example, percentage of natural minerals ${ }^{8,49}$. Domesticated animals or plants are perceived as more natural compared with GM animals or GM plants ${ }^{8}$. The absence of additives is another important aspect of perceived naturalness ${ }^{50,51}$. People perceive orange juice with added vitamin $\mathrm{C}$ as less natural compared with orange juice with removed vitamin $C$, for example ${ }^{51}$. These findings suggest that the idea of some sort of contagion or harm to purity negatively influences perceived naturalness ${ }^{47}$.

The preference for natural foods could be driven by instrumental (for example, health) or ideational reasons (for example, moral reasons $)^{47}$. Should the latter be the dominant motivation, it would be very difficult or even impossible to change consumers' preferences ${ }^{47,52}$. However, some empirical evidence shows that instrumental beliefs strongly contribute to the natural-is-better heuristic ${ }^{53}$. It could therefore be possible to influence consumers' preferences toward foods they perceive as less natural, if they provide tangible benefits.

Reliance on the natural-is-better heuristic for risk evaluation may introduce bias in decisions. For example, compared with experts, laypeople tend to be less concerned about hazards of natural origin, such as Listeria or Campylobacter ${ }^{4}$. The same benefits, such as a rich harvest, are perceived as less valuable for a farmer when they are the results of GM crops compared with traditionally bred crops, with the lack of perceived naturalness of GT seemingly the reason ${ }^{23}$. Perceived naturalness has also been shown to be important for the acceptance of functional foods ${ }^{55}$ or cultured meat ${ }^{56}$. Both are the results of human processing and interference with otherwise familiar products.

\section{Framing effects}

The framing of information influences people's decisions, and how a food technology is described influences consumers ${ }^{57}$. For example, the US media has labelled lean, finely textured beef as 'pink slime' and as a consequence, consumers have been influenced by the negative label when assessing the health risks associated with the consumption of ground beef ${ }^{58}$. Similarly, it has been shown that the use of $E$ numbers for food additives reduces their perceived naturalness compared with the situation in which the food additives are presented without $\mathrm{E}$ numbers ${ }^{48,59}$. How cultured meat is labelled (for example, laboratory grown meat, clean meat, animal-free meat) influences the valence of the evoked associations, which in turn help shape attitudes and behavioural intentions ${ }^{60}$. The labels used for new food technologies can, therefore, have a strong impact on consumer acceptance.

\section{Individual differences among people}

People differ in their preferences and values, which may explain some of the observed differences in consumer acceptance of agri-food technologies. Prior research has mostly examined the impacts of food technology neophobia, disgust sensitivity and cultural factors on individual differences in risk perception and acceptance. However, a recent study suggests that people's general personality traits, such as openness and conscientiousness, also influence their preference for GM foods ${ }^{61}$.

Food technology neophobia. Food technology neophobia is a personality trait that influences consumers' willingness to accept new food technologies ${ }^{11,62}$. This personality trait is only weakly correlated with food neophobia ${ }^{11,63}$, which is the tendency to reject unfamiliar foods ${ }^{10}$. People with more food knowledge seem to have lower food technology neophobia scores compared with people with less food knowledge ${ }^{64}$. However, consumers concerned about sustainability aspects of their food consumption tend to have higher food technology neophobia scores compared with consumers who are less concerned about sustainability ${ }^{64}$. The impact of food technology neophobia on the acceptance of novel food technologies seems to be not restricted to high-income countries, but has also been an important factor for the lack of food technology acceptance in Uganda, a low-income country ${ }^{65}$. Thus, there is some evidence that food technology neophobia is a universal factor that influences acceptance of innovations related to food.

Food neophobia has a somewhat mixed impact on attitudes toward new food technologies: it has no association with attitudes toward GT ${ }^{66}$ but does have with 3D-printed food ${ }^{67}$. Consumers may perceive 3D-printed food not only as produced by a new technology but also as a novel food, such as insect-based products ${ }^{15}$. In the case of GT, consumers may perceive the food as familiar and may be willing to taste $i^{68}$ but may have negative feelings toward the technology.

Disgust sensitivity. Disgust is one of the evolved mechanisms that motivate people to avoid pathogens and to show disease-avoidance behaviour ${ }^{69}$. In an environment with limited food supply, people have to make trade-offs between avoiding disease and not forgoing calories. Depending on the environment to which people have adapted, whether food is scarce or more abundant, different strategies may have evolved. People living in the latter environment may react more often with disgust compared with people living in the former ${ }^{70}$.

Various instruments have been proposed to measure individual differences in disgust sensitivity; some scales focus on the pathogen, the sexual or the moral domain ${ }^{71}$, whereas other measures are applied to the food domain only ${ }^{72}$. A recently published food disgust scale predicts people's tendency to experience feelings of disgust when the food has some cues that might be considered indications 
of pathogen presence (for example, mould) or contamination (for example, touched by another person $)^{72}$. Undoubtedly, disgust sensitivity can have an impact, not only on people's hygienic behaviour (for example, hand washing, kitchen hygiene $)^{73,74}$, but also on their food selection behaviours and routines ${ }^{75}$. Concerning the acceptance of food technologies, researchers have just started to understand the influence of disgust. There are some controversies about whether disgust plays a role and effect sizes vary by the technological application ${ }^{33}$. For instance, state (that is, experienced in a situation) and trait (that is, personality factor) disgust are found to be linked to the rejection of artificial meat and milk, as well as GM foods ${ }^{33}$. In the latter case, associations with food contamination and perceived unnaturalness may make GM foods not only disgusting but also morally repugnant because of the perceived violation of nature ${ }^{76}$. Furthermore, people with higher disgust sensitivity may be less willing to accept GM food compared with people with lower disgust sensitivity. Such reasoning is supported by the finding that GM opponents have a higher disgust sensitivity than GM proponents ${ }^{32}$. Similar results have been found for other food technologies ${ }^{33}$. The explanatory power of disgust sensitivity regarding the acceptance of novel food technologies might be biased by language inconsistencies, however ${ }^{77}$. It has been argued that in the English language, people also use the term 'disgust' to describe non-specific feelings, such as 'bothered' and 'upset" ${ }^{77}$. Therefore, it is not fully clear whether the disgust scales in the English language measure specific disgust or a general negative feeling. Despite the plausibility of the impact of disgust on the acceptance of novel food technologies, additional empirical support for such a claim would be desirable.

Cultural factors. The cultural theory of risk perception postulates that worldviews-beliefs about the functioning and values regarding society-are important determinants of the perspectives that people form about risks ${ }^{78}$. This paradigm maintains that people are either group or individual oriented, and they either prefer adhering to many rules to control human behaviour or believe that few rules are necessary ${ }^{79,80}$. On the basis of these dichotomies, four basic worldviews can be distinguished: hierarchical, fatalistic, individualistic and egalitarian. People in the US with more egalitarian worldviews seemed to be more concerned about food irradiation, GT or pesticides in foods compared with people with less egalitarian worldviews ${ }^{80}$. In a study conducted in the UK, hierarchical, individualistic, egalitarian and fatalistic worldviews were non-significantly correlated with risk perceptions of GT and only weakly associated with risk perceptions as regards food coloring ${ }^{81}$. Worldviews that are measured using a two-dimensional scale that distinguishes hierarchical-egalitarian worldviews from individualistic-communitarianistic principles were also found unrelated to risk/benefit perceptions with respect to nanotechnology $y^{82}$. Nevertheless, such worldviews exert an important effect on the interpretation of new information about nanotechnology. Hierarchical individualists lean more toward perceiving benefits than risks, whereas egalitarian communitarians tend to more readily discern risks than benefits after being exposed to new information about nanotechnology ${ }^{82}$.

Another approach for measuring cultural differences is based on the value concept ${ }^{83}$. This method is underlain by the assumption that basic values (for example, security, power) influence people's attitudes and behaviours and that the importance of various values may differ across cultures. The explanatory power of this approach has been questioned ${ }^{84}$ because Schwartz's well-known value scale $^{83}$, as well as other value measures, is only weakly correlated with risk perception ${ }^{84}$.

The persuasive power of the cultural theory of risk perception stands in contrast to its explanatory power ${ }^{84}$. The type of hazard, how cultural values are measured, and whether information about a technology is provided seem to strongly influence the observed association. The cultural theory could be more strongly related to the acceptance of various risk regulation measures than with risk perception-an issue that would be an interesting avenue for future research.

\section{Acceptance of selected food technologies}

The voluntariness of being exposed to a risk is an important factor for its acceptance ${ }^{85}$. If consumers have the impression of being in control of their exposure to a food hazard, a higher risk is accepted compared with the situation where consumers lack this sense of voluntary exposure to a hazard ${ }^{54}$. The consumption of alcohol and an unbalanced diet, for example, are associated with certain benefits, whereas novel food technologies such as GT are not linked to any tangible benefits for many consumers.

The psychometric paradigm has been used to further explain why people are concerned about some hazards but not about oth$\mathrm{ers}^{27}$. The results of these cited studies suggest that for laypeople, the qualitative characteristics of a hazard are more important than fatalities. Perceived dread and familiarity have been shown as important characteristics for the perception of food hazards ${ }^{86-88}$. GT, food irradiation and pesticide residues are perceived as unknown and dreadful risks; hazards, such as excessive intake of alcohol and calories, are perceived as familiar and less severe risks ${ }^{86-88}$. The likelihood and the possible negative consequences of a food hazard have a stronger impact on experts' risk perceptions compared with laypeople's assessments ${ }^{27,54}$.

Many food technologies have been introduced and, of course, not all have been rejected by consumers ${ }^{89}$. Unless there is a public discourse about a novel food technology, consumers may be unaware that it exists or is frequently used. If a food technology can be identified by its specific characteristics (for example, perceived as dreadful or unnatural), then nongovernmental organizations, scientists or the media may help a public discourse to emerge, and people may start to have negative perceptions of a food technology or even reject it. In the following sections, we focus on some selected food technologies for which social science research has examined the factors influencing their acceptance.

\section{Gene technology}

There has been comprehensive research on public acceptance of agricultural and food technologies, and that conducted in Europe shows large differences in how GT is perceived across countries ${ }^{7,90}$. The 2010 Eurobarometer, including representative samples with participants from 32 countries, also shows that opponents of GM foods outnumber supporters by three to one ${ }^{7}$. The main reasons for this low acceptance are perceived risks, lack of perceived benefits and perceived unnaturalness ${ }^{7}$.

People generally lack knowledge about $\mathrm{GT}^{91}$; therefore, they may rely on the affect, trust or naturalness heuristics to evaluate GM foods. The findings of empirical studies indicate the effects of all three heuristics on laypeople's perceptions. Studies conducted in different countries across global regions find that social trust influences laypeople's benefit and risk perceptions of GM foods ${ }^{41,92,93}$. These perceptions further influence the acceptance of GM foods. However, the importance of perceived risks and benefits for the acceptance of GM foods has been questioned ${ }^{76}$ because information about risks and benefits has little impact on the acceptance of GM foods ${ }^{94}$. This finding does not necessarily imply that perceived benefits are not important for the acceptance of GM foods. Rather, the results suggest that if there are no tangible benefits (that is, cheaper, better tasting food) for consumers, the perceived unnaturalness of GM foods may play an important role in the lack of acceptance ${ }^{95}$.

People's acceptance of GT differs across applications? ${ }^{7}$. The public seems to be more sceptical of GM foods and GM crops compared with genetic testing or medical applications ${ }^{96}$. Furthermore, in the food domain, not all genetic modifications are perceived in 
the same way. When genes are exchanged between different species, laypeople are more worried ${ }^{97}$. Similarly, cisgenic apples have received higher support than transgenic apples in all European Union countries? ${ }^{7}$. It has also been shown that inserting a gene in an organism decreases its perceived naturalness more than deleting a gene $^{51}$. Even though GM foods are negatively perceived overall, there are differences across applications and among consumers in how GT is evaluated.

\section{Nanotechnology}

In food products, engineered nanoparticles are already used as additives, and future applications of the technology in the food and the agricultural domains are under development ${ }^{98}$. There was substantial concern when the first nanotechnology applications in the food domain were discussed, as well as apprehension that nanotechnology could suffer a similar fate as that of $\mathrm{GT}^{99,100}$. Surveys found that for laypeople, the benefits of nanotechnology outweighed the risks, yet a relatively large percentage of the respondents did not answer the risk-versus-benefit question ${ }^{101}$. In other words, the participants were unable to assess the risks and the benefits of nanotechnology. This finding suggests that the perception of nanotechnology may still be rather malleable.

Several fundamental differences between GT and nanotechnology are relevant for people's perceptions. The latter is related to a physical transformation of materials, whereas the former involves the manipulation of biological entities that may be perceived as tampering with nature ${ }^{8}$. Furthermore, physical transformation has a much lower impact on perceived naturalness compared with chemical or even biological transformation ${ }^{8}$.

In some studies, the majority of the participants had no prior knowledge about nanotechnology ${ }^{82}$; therefore, they had to form an opinion when filling in the questionnaire. Given the participants' low level of technological knowledge, it is not surprising that several studies found that affect associated with nanotechnology was a strong predictor of perceived risks and that trust in the government regulations of this sector also influenced laypeople's perceptions ${ }^{101}$. People's cultural values had an effect on how they interpreted the information about nanotechnology $\mathrm{y}^{82}$.

Even though nanotechnology will most likely never be perceived as unnatural or as tampering with nature (as is the case with GT), a possible increase in risk perception in the future cannot be completely ruled out. The media has the power to change public perception of nanotechnology ${ }^{100}$. Furthermore, government regulations may have an impact on how laypeople perceive food products containing nanomaterials ${ }^{102}$. For example, mandatory labelling of nanotechnology in food products could be misinterpreted as a warning signal by consumers ${ }^{102}$. Why would there be a label on a product if nanotechnology was not associated with some risks? Labelling does not only inform consumers, but it may also influence the perception of a food technology.

\section{Cultured meat}

Based on stem cell technology, in vitro or cultured meat is grown in the laboratory ${ }^{103}$. It has been proposed as a more sustainable and animal-friendly alternative to the conventional production of meat through livestock. In studies examining the stated acceptance of cultured meat, the use of different descriptions and labels may have been an important factor in explaining why the measured acceptance substantially differs across studies ${ }^{104}$. Importantly, how cultured meat is described influences the perceived naturalness of the product ${ }^{105}$. Consumers' spontaneous reactions to the idea of laboratory-produced meat are the perception of unnaturalness and the feeling of disgust ${ }^{106,107}$. Perceived naturalness has also been shown to be an important factor influencing the acceptance of cultured meat ${ }^{59,105,108}$. Consumers who perceive cultured meat as unnatural find the risks less acceptable compared with conventional meat $^{59}$ and are more disgusted ${ }^{105}$ than consumers who perceive cultured meat as more natural. For consumers' acceptance of cultured meat, it will be crucial how the product will be described and what label will be used.

Cultured meat has animal welfare benefits, of course. How information about this aspect influences acceptance has not been examined, however ${ }^{56}$. Some research suggests that the importance of this aspect may be limited because consumers use various cognitive strategies for the justification of raising and killing animals for meat consumption $^{109}$. Therefore, for many consumers, the animal welfare argument may be less important for the acceptance of cultured meat compared with other aspects, such as perceived naturalness, taste or price.

\section{Food irradiation}

The label used for a food technology can have a large impact on how the technology and its acceptability are perceived. The term 'food irradiation' evokes not only negative associations, such as a nuclear plant or cell destruction ${ }^{110}$, but the affect associated with nuclear power seems to influence the perception of this food technology $y^{3}$. Consumers for whom nuclear power is very negatively tagged, perceive food irradiation as riskier and less beneficial compared with consumers for whom nuclear power is neutral or positive ${ }^{3}$. The affect heuristic produces biased perceptions that may even result in the perception that irradiated food poses a health risk ${ }^{111}$. Experimental studies show how important the name of a food technology is for its perception. Products labelled as 'treated with irradiation' are perceived to be of lower quality compared with products labelled as 'treated with ionization's. The latter term does not seem to elicit associations as negative as food irradiation does. Therefore, it is not surprising that irradiated food has been evaluated as unacceptable by consumers ${ }^{112}$ and as a technology that substantially decreases the perceived utility of foods.

\section{Conclusions}

A broad set of agri-food technologies is needed to produce safe, healthy, sustainable foods, and technologies labelled 'disruptive' are seen as part of the solution to food security in the era of climate change and population growth. Most disruptive innovations that fundamentally changed an industry are from outside the food domain ${ }^{113}$. Figure 1 further shows the limited number of disruptive innovations in the food system. In order to meet the challenges posed by climate change, population growth and disruptions in the food chain, there is clear need for disruptive innovations. For the successful introduction of such innovations, societal acceptance needs to be examined at an early stage of development.

For consumers in general, the production of foods is increasingly a black box. The prevalence of highly processed convenience foods and declining cooking skills ${ }^{114}$ further alienate many consumers from how food is produced and how meals are prepared. Future studies need to examine whether a crisis such as COVID-19 influences consumers' perceptions of food technologies, because canned and frozen foods, for example, are essential for stockpiling. Due to their lack of knowledge and familiarity with most of these food technologies, they often rely on simple heuristics when evaluating them. The experiential system is more important than the analytical system in how novel food technologies are perceived ${ }^{17}$. Generally, consumers' reliance on the natural-is-better and the affect heuristics is one reason for their lack of acceptance of some novel food technologies. As Fig. 2 illustrates, both the aspects of the technology and the characteristics of the person further influence their perception. If a technology is viewed as unnatural, dreadful, and uncontrollable, and if people are not voluntarily exposed to it, its acceptance tends to be low. Person-related factors, such as food technology neophobia, disgust sensitivity and cultural values, further influence the perception of a technology. The factors that are most crucial for the lack of acceptance differ across food technologies, however. 


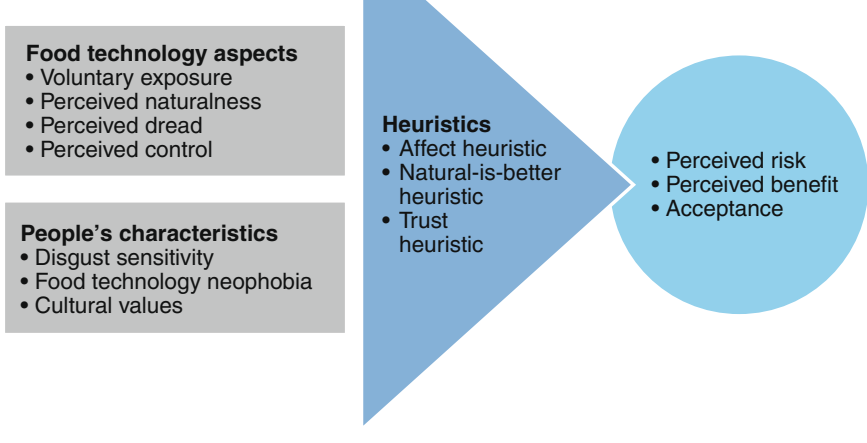

Fig. 2 | Factors influencing the perception of food technologies. How a food technology is perceived by consumers depends both on the perceived aspects of a food technology and on the individual characteristics of the consumers. Furthermore, both of these factors influence the heuristics that consumers rely on when evaluating the benefits, risks and acceptance of food technologies.

The natural-is-better heuristic is especially relevant for people's acceptance of novel food technologies and for their evaluation of food. The food industry players are aware of how important perceived naturalness is for consumers; therefore, the naturalness of its products is emphasized in marketing campaigns. It may seem strange that on one hand, the food industry struggles with consumers' acceptance of novel food technologies due to the lack of perceived naturalness; on the other hand, the food industry emphasizes the naturalness of its products, which may further strengthen consumers' belief that natural products are superior. Similarly, the promotion of organic foods may foster the idea that natural foods are better despite the lack of scientific support for a lower environmental impact of organically produced foods ${ }^{115}$. Technological innovations and scientific progress have resulted in high levels of food safety and food security in many countries. The somewhat ironic consequence is that, at least in many developed countries, the naturalness of food is highly valued because food safety and security are considered guaranteed.

Progress toward a more sustainable, more secure, safer food system is difficult to envisage without novel food technologies. Therefore, general scepticism regarding technologies in the food domain will remain a challenge. In this Review, we have presented some factors that help explain why people often evaluate novel food technologies in a rather negative way. For various reasons, condemnation of technologies is problematic, in our view. The deep freezer can be used to store ice cream or vegetables that are most likely richer in vitamins than fresh ones bought in the supermarket that are not frozen but stored for days between harvest and consumption. Even an extruder that produces highly processed foods can be used for foods (for example, whole-grain pasta) that contribute to a balanced diet. The question is for what purpose, not whether a technology is used. Society should move towards a healthier diet, but it should be recognized that food technologies need to be part of such a trend instead of being perceived as barriers.

We have also identified some knowledge gaps that future research should address. Most studies in this field have been conducted in developed countries, mainly in selected European countries or North America. For many of the topics covered in this Review, there is a lack of studies from Asian or African countries. For example, it needs to be known whether the concept of naturalness is equally important in developing countries. Another fruitful avenue for future research is the impact of cultural values on the acceptance of novel food technologies. The few studies that have examined the impact of cultural values have focused on the differences among the people in a certain country but have failed to address the question of whether cultural values also explain differences in perceptions across countries.

Lastly, genome editing of crops has gained much progress in recent years, and countries differ in how CRISPR-engineered crops are regulated and whether or not they are perceived similarly to genetically modified organisms ${ }^{116}$. There is some indication that consumers generally perceive CRISPR-engineered crops more positively than $\mathrm{GT}^{7}$. Perceptions of new food technologies are malleable, however. Future studies need to examine how different genome editing technologies are perceived by consumers and which aspects of these technologies most strongly influence their acceptance.

Received: 5 June 2019; Accepted: 13 May 2020;

Published online: 17 June 2020

\section{References}

1. Frewer, L. J. et al. Consumer response to novel agri-food technologies: Implications for predicting consumer acceptance of emerging food technologies. Trends Food Sci. Technol. 22, 442-456 (2011).

2. Frewer, L. J. et al. Public perceptions of agri-food applications of genetic modification: a systematic review and meta-analysis. Trends Food Sci. Technol. 30, 142-152 (2013).

3. Bearth, A. \& Siegrist, M. "As long as it is not irradiated" Influencing factors of US consumers' acceptance of food irradiation. Food Qual. Preference 71 , 141-148 (2019).

4. Cardello, A. V. Consumer concerns and expectations about novel food processing technologies: effects on product liking. Appetite 40, 217-233 (2003).

5. Lusk, J. L., Roosen, J. \& Bieberstein, A. Consumer acceptance of new food technologies: causes and roots of controversies. Annu. Rev. Resour. Econ. 6, 381-405 (2014).

6. Attitudes Towards the Impact of Digitisation and Automation on Daily Life Special Eurobarometer 460 (European Commission, 2017).

7. Gaskell, G. et al. The 2010 Eurobarometer on the life sciences. Nat. Biotechnol. 29, 113-114 (2011).

8. Rozin, P. The meaning of "natural". Psychol. Sci. 16, 652-658 (2005).

9. Roman, S., Sanchez-Siles, L. M. \& Siegrist, M. The importance of food naturalness for consumers: results of a systematic review. Trends Food Sci. Technol. 67, 44-57 (2017).

10. Pliner, P. \& Hobden, K. Development of a scale to measure the trait of food neophobia in humans. Appetite 19, 105-120 (1992).

11. Cox, D. N. \& Evans, G. Construction and validation of a psychometric scale to measure consumers' fears of novel food technologies: the food technology neophobia scale. Food Qual. Preference 19, 704-710 (2008).

12. Dordevic, D. \& Buchtova, H. Factors influencing sushi meal as representative of non-traditional meal: consumption among Czech consumers. Acta Alimentaria 46, 76-83 (2017).

13. Siegrist, M. \& Hartmann, C. Impact of sustainability perception on consumption of organic meat and meat substitutes. Appetite 132, 196-202 (2019).

14. Wardle, J., Parmenter, K. \& Waller, J. Nutrition knowledge and food intake. Appetite 34, 269-275 (2000).

15. Hartmann, C. \& Siegrist, M. Consumer perception and behaviour regarding sustainable protein consumption: a systematic review. Trends Food Sci. Technol. 61, 11-25 (2017).

16. Connor, M. \& Siegrist, M. Factors influencing peoples' acceptance of gene technology: the role of knowledge, health concerns, naturalness, and social trust. Sci. Commun. 32, 514-538 (2011).

17. Slovic, P., Finucane, M. L., Peters, E. \& MacGregor, D. G. Risk as analysis and risk as feelings: some thoughts about affect, reason, risk, and rationality. Risk Anal. 24, 311-322 (2004).

18. Gigerenzer, G. \& Gaissmaier, W. Heuristic decision making. Annu. Rev. Psychol. 62, 451-482 (2011).

19. Kahneman, D., Slovic, P. \& Tversky, A. Judgment Under Uncertainty: Heuristics and Biases (Cambridge Univ. Press, 1982).

20. Kahneman, D. \& Frederick, S. in The Cambridge Handbook of Thinking and Reasoning (eds. Holyoak, K. J. \& Morrison, G.) 267-293 (Cambridge Univ. Press, 2005).

21. Montibeller, G. \& von Winterfeldt, D. Cognitive and motivational biases in decision and risk analysis. Risk Anal. 35, 1230-1251 (2015).

22. Gigerenzer, G., Todd, P. M. \& the ABC Research Group Simple Heuristics That Make us Smart (Oxford Univ. Press, 1999).

23. Siegrist, M., Hartmann, C. \& Sütterlin, B. Biased perception about gene technology: how perceived naturalness and affect distort benefit perception. Appetite 96, 509-516 (2016). 
24. Gigerenzer, G. Why heuristics work. Perspect. Psychol. Sci. 3, 20-29 (2008).

25. Finucane, M. L., Alhakami, A., Slovic, P. \& Johnson, S. M. The affect heuristic in judgments of risks and benefits. J. Behav. Decis. Making 13, 1-17 (2000).

26. Pachur, T., Hertwig, R. \& Steinmann, F. How do people judge risks: availability heuristic, affect heuristic, or both? J. Exp. Psychol. Appl. 18, 314-330 (2012).

27. Slovic, P. Perception of risk. Science 236, 280-285 (1987).

28. Townsend, E. \& Campbell, S. Psychological determinants of willingness to taste and purchase genetically modified food. Risk Anal. 24, 1385-1393 (2004)

29. Connor, M. \& Siegrist, M. The power of association: its impact on willingness to buy GM food. Hum. Ecol. Risk Assess. 17, 1142-1155 (2011).

30. Siegrist, M., Cousin, M.-E., Kastenholz, H. \& Wiek, A. Public acceptance of nanotechnology foods and food packaging: the influence of affect and trust. Appetite 49, 459-466 (2007).

31. Sokolowska, J. \& Sleboda, P. The inverse relation between risks and benefits: the role of affect and expertise. Risk Anal. 35, 1252-1267 (2015).

32. Scott, S. E., Inbar, Y. \& Rozin, P. Evidence for absolute moral opposition to genetically modified food in the United States. Persp. Psychol. Sci. 11, 315-324 (2016).

33. Egolf, A., Hartmann, C. \& Siegrist, M. When evolution works against the future: disgust's contributions to the acceptance of new food technologies. Risk Anal. 39, 1546-1559 (2019).

34. Earle, T. C. Trust in risk management: a model-based review of empirical research. Risk Anal. 30, 541-574 (2010).

35. Siegrist, M. Trust and risk perception: a critical review of the literature. Risk Anal. https://doi.org/10.1111/risa.13325 (2019).

36. Hobbs, J. E. Information asymmetry and the role of traceability systems. Agribusiness 20, 397-415 (2004).

37. Siegrist, M. \& Cvetkovich, G. Perception of hazards: the role of social trust and knowledge. Risk Anal. 20, 713-719 (2000).

38. Freudenburg, W. R. Risk and recreancy: Weber, the division of labor, and the rationality of risk perceptions. Soc. Forces 71, 909-932 (1993).

39. Luhmann, N. Vertrauen: Ein Mechanismus der Reduktion sozialer Komplexität (Enke, 1989)

40. Roosen, J. et al. Trust and willingness to pay for nanotechnology food. Food Policy 52, 75-83 (2015).

41. Siegrist, M. The influence of trust and perceptions of risks and benefits on the acceptance of gene technology. Risk Anal. 20, 195-203 (2000).

42. Yue, C. Y., Zhao, S. L., Cummings, C. \& Kuzma, J. Investigating factors influencing consumer willingness to buy GM food and nano-food. I. Nanopart. Res. 17, 283 (2015).

43. Bratanova, B., Morrison, G., Fife-Schaw, C., Chenoweth, J. \& Mangold, M. Restoring drinking water acceptance following a waterborne disease outbreak: the role of trust, risk perception, and communication. J. Appl. Social Psychol. 43, 1761-1770 (2013).

44. Earle, T. C. \& Cvetkovich, G. T. Social Trust: Toward a Cosmopolitan Society (Praeger, 1995).

45. Allum, N. An empirical test of competing theories of hazard-related trust: the case of GM food. Risk Anal. 27, 935-946 (2007).

46. Siegrist, M., Earle, T. C. \& Gutscher, H. (eds.) Trust in Cooperative Risk Management: Uncertainty and Scepticism in the Public Mind (Earthscan, 2007).

47. Rozin, P., Fischler, C. \& Shields-Argeles, C. European and American perspectives on the meaning of natural. Appetite 59, 448-455 (2012).

48. Evans, G., de Challemaison, B. \& Cox, D. N. Consumers' ratings of the natural and unnatural qualities of foods. Appetite 54, 557-563 (2010).

49. Rozin, P. Naturalness judgments by lay Americans: Process dominates content in judgments of food or water acceptability and naturalness. Judgment Decis. Making 1, 91-97 (2006).

50. Rozin, P., Fischler, C. \& Shields-Argeles, C. Additivity dominance: Additivites are more potent and more often lexicalized across languages than are "subtractives". Judgment Decis. Making 4, 475-478 (2009).

51. Scott, S. E. \& Rozin, P. Are additives unnatural? Generality and mechanisms of additivity dominance. Judgment Decis. Making 12, 572-583 (2017).

52. Rozin, P. et al. Preference for natural: instrumental and ideational/mora motivations, and the contrast between foods and medicines. Appetite 43, 147-154 (2004).

53. Li, M. \& Chapman, G. B. Why do people like natural? Instrumental and ideational bases for the naturalness preference. J. Appl. Social Psychol. 42, 2859-2878 (2012).

54. Siegrist, M., Hubner, P. \& Hartmann, C. Risk prioritization in the food domain using deliberative and survey methods: differences between experts and laypeople. Risk Anal. 38, 504-524 (2018).

55. Aschemann-Witzel, J. \& Grunert, K. G. Attitude towards resveratrol as a healthy botanical ingredient: The role of naturalness of product and message. Food Qual. Preference 57, 126-135 (2017).

56. Bryant, C. J., Anderson, J. E., Asher, K. E., Green, C. \& Gasteratos, K. Strategies for overcoming aversion to unnaturalness: the case of clean meat. Meat Sci. 154, 37-45 (2019).
57. Tversky, A. \& Kahneman, D. The framing of decisions and the psychology of choice. Science 211, 453-458 (1981).

58. Runge, K. K., Chung, J. H., Su, L. Y. F., Brossard, D. \& Scheufele, D. A. Pink slimed: media framing of novel food technologies and risk related to ground beef and processed foods in the US. Meat Sci. 143, 242-251 (2018).

59. Siegrist, M. \& Sütterlin, B. Importance of perceived naturalness for acceptance of food additives and cultured meat. Appetite 113, 320-326 (2017).

60. Bryant, C. J. \& Barnett, J. C. What's in a name? Consumer perceptions of in vitro meat under different names. Appetite 137, 104-113 (2019).

61. Lin, W., Ortega, D. L., Caputo, V. \& Lusk, J. L. Personality traits and consumer acceptance of controversial food technology: A cross-country investigation of genetically modified animal products. Food Qual. Preference 76, 10-19 (2019).

62. Evans, G., Kermarrec, C., Sable, T. \& Cox, D. N. Reliability and predictive validity of the Food Technology Neophobia Scale. Appetite 54, 390-393 (2010).

63. Schnettler, B. et al. Psychometric analysis of the Food Technology Neophobia Scale in a Chilean sample. Food Qual. Preference 49, 176-182 (2016)

64. Cavaliere, A. \& Ventura, V. Mismatch between food sustainability and consumer acceptance toward innovation technologies among Millenial students: the case of shelf life extension. J. Cleaner Prod. 175, 641-650 (2018).

65. De Steur, H., Odongo, W. \& Gellynck, X. Applying the food technology neophobia scale in a developing country context. A case-study on processed matooke (cooking banana) flour in Central Uganda. Appetite 96, 391-398 (2016).

66. Lähteenmäki, L. et al. Acceptability of genetically modified cheese presented as real product alternative. Food Qual. Preference 13, 523-533 (2002).

67. Brunner, T. A., Delley, M. \& Denkel, C. Consumers' attitudes and change of attitude toward 3D-printed food. Food Qual. Preference 68, 389-396 (2018).

68. Aerni, P., Scholderer, J. \& Ermen, D. How would Swiss consumers decide if they had freedom of choice? Evidence from a field study with organic, conventional and GM corn bread. Food Policy 36, 830-838 (2011).

69. Curtis, V. Why disgust matters. Philos. Trans. R. Soc. B 366 , 3478-3490 (2011).

70. Hoefling, A. et al. When hunger finds no fault with moldy corn: food deprivation reduces food-related disgust. Emotion 9, 50-58 (2009).

71. Olatunji, B. O. et al. The disgust scale: item analysis, factor structure, and suggestions for refinement. Psychol. Assess. 19, 281-297 (2007).

72. Hartmann, C. \& Siegrist, M. Development and validation of the Food Disgust Scale. Food Qual. Preference 63, 38-50 (2018).

73. Ammann, J., Siegrist, M. \& Hartmann, C. The influence of disgust sensitivity on self-reported hygiene behaviour. Food Control 102, 131-138 (2019).

74. Curtis, V., de Barra, M. \& Aunger, R. Disgust as an adaptive system for disease avoidance behaviour. Philos. Trans. R. Soc. B 366, 389-401 (2011).

75. Egolf, A., Siegrist, M. \& Hartmann, C. How people's food disgust sensitivity shapes their eating and food behaviour. Appetite 127, 28-36 (2018).

76. Scott, S. E., Inbar, Y., Wirz, C. D., Brossard, D. \& Rozin, P. An overview of attitudes toward genetically engineered food. Annu. Rev. Nutr. 38, 459-479 (2018).

77. Royzman, E., Cusimano, C. \& Leeman, R. F. What lies beneath? Fear vs. disgust as affective predictors of absolutist opposition to genetically modified food and other new technologies. Judgment Decis. Making 12, 466-480 (2017).

78. Douglas, M. \& Wildavsky, A. Risk and culture: An Essay on the Selection of Technological and Environmental Dangers (Univ. California Press, 1982).

79. Dake, K. Orienting dispositions in the perception of risk: An analysis of contemporary worldviews and cultural biases. J. Cross-Cultural Psychol. 22, 61-82 (1991).

80. Peters, E. \& Slovic, P. The role of affect and worldviews as orienting dispositions in the perception and acceptance of nuclear power. J. Appl. Social Psychol. 26, 1427-1453 (1996).

81. Marris, C., Langford, I. H. \& O'Riordan, T. A quantitative test of the cultural theory of risk perceptions: comparison with the psychometric paradigm. Risk Anal. 18, 635-647 (1998).

82. Kahan, D. M., Braman, D., Slovic, P., Gastil, J. \& Cohen, G. Cultural cognition of the risks and benefits of nanotechnology. Nat. Nanotechnol. 4, 87-90 (2009).

83. Schwartz, S. H. Universals in the content and structure of values: Theoretical advances and empirical tests in 20 countries. Adv. Exp. Social Psychol. 25, 1-65 (1992).

84. Sjöberg, L. Factors in risk perception. Risk Anal. 20, 1-11 (2000)

85. Starr, C. Social benefit versus technological risk. Science 165, 1232-1238 (1969)

86. Fife-Schaw, C. \& Rowe, G. Extending the application of the psychometric approach for assessing public perceptions of food risks: Some methodological considerations. J. Risk Res. 3, 167-179 (2000). 
87. Kirk, S. F. L., Greenwood, D., Cade, J. E. \& Pearman, A. D. Public perception of a range of potential food risks in the United Kingdom. Appetite 38, 189-197 (2002).

88. Sparks, P. \& Shepherd, R. Public perceptions of the potential hazards associated with food production and food consumption: an empirical study. Risk Anal. 14, 799-806 (1994).

89. Frewer, L. J. Consumer acceptance and rejection of emerging agrifood technologies and their applications. Eur. Rev. Agric. Econ. 44, 683-704 (2017).

90. Food Safety in the EU Special Eurobarometer Wave EB91.3 (European Commission, 2019).

91. Mielby, H., Sandoe, P. \& Lassen, J. The role of scientific knowledge in shaping public attitudes to GM technologies. Public Understanding Sci. 22, 155-168 (2013).

92. Prati, G., Pietrantoni, L. \& Zani, B. The prediction of intention to consume genetically modified food: Test of an integrated psychosocial model. Food Qual. Preference 25, 163-170 (2012).

93. Zhang, Y. Y. et al. Application of an integrated framework to examine Chinese consumers' purchase intention toward genetically modified food. Food Qual. Preference 65, 118-128 (2018).

94. Frewer, L. J., Scholderer, J. \& Bredahl, L. Communicating about the risks and benefits of genetically modified foods: the mediating role of trust. Risk Anal. 23, 1117-1133 (2003).

95. Gaskell, G. et al. Biotechnology and the European public. Nat. Biotechnol. 18, 935-938 (2000).

96. Connor, M. \& Siegrist, M. Sorting biotechnology applications: Results of multidimensional scaling (MDS) and cluster analysis. Public Understanding Sci. 22, 128-136 (2013).

97. Kronberger, N., Wagner, W. \& Nagata, M. How natural is "more natural"? The role of method, type of transfer, and familiarity for public perceptions of cisgenic and transgenic modification. Sci. Commun. 36 106-130 (2014).

98. Peters, R. J. B. et al. Nanomaterials for products and application in agriculture, feed and food. Trends Food Sci. Technol. 54, 155-164 (2016)

99. Currall, S. C., King, E. B., Lane, N., Madera, J. \& Turner, S. What drives public acceptance of nanotechnology? Nat. Nanotechnol. 1, 153-155 (2006).

100. Duncan, T. V. The communication challenges presented by nanofoods. Nat. Nanotechnol. 6, 683-688 (2011).

101. Satterfield, T., Kandlikar, M., Beaudrie, C. E. H., Conti, J. \& Herr Harthorn, B. Anticipating the perceived risk of nanotechnologies. Nat. Nanotechnol. 4 752-758 (2009).

102. Siegrist, M. \& Keller, C. Labeling of nanotechnology consumer products can influence risk and benefit perceptions. Risk Anal. 31, 1762-1769 (2011)

103. Post, M. J. Cultured meat from stem cells: challenges and prospects. Meat Sci. 92, 297-301 (2012).

104. Bryant, C. \& Barnett, J. Consumer acceptance of cultured meat: a systematic review. Meat Sci. 143, 8-17 (2018)
105. Siegrist, M., Sutterlin, B. \& Hartmann, C. Perceived naturalness and evoked disgust influence acceptance of cultured meat. Meat Sci. 139, 213-219 (2018).

106. Marcu, A. et al. Analogies, metaphors, and wondering about the future: lay sense-making around synthetic meat. Public Understanding Sci. 24, 547-562 (2015).

107. Verbeke, W. et al. 'Would you eat cultured meat?': Consumers' reactions and attitude formation in Belgium, Portugal and the United Kingdom. Meat Sci. 102, 49-58 (2015).

108. Wilks, M. \& Phillips, C. J. C. Attitudes to in vitro meat: a survey of potential consumers in the United States. PLoS ONE 12, e0171904 (2017).

109. Rothgerber, H. Real men don't eat (vegetable) quiche: masculinity and the justification of meat consumption. Psychol. Men Masculinity 14, 363-375 (2013).

110. Behrens, J. H., Barcellos, M. N., Frewer, L. J., Nunes, T. P. \& Landgraf, M. Brazilian consumer views on food irradiation. Innovative Food Sci. Emerg. Technol. 10, 383-389 (2009).

111. Finten, G., Garrido, J. I., Aguero, M. V. \& Jagus, R. J. Irradiated ready-to-eat spinach leaves: how information influences awareness towards irradiation treatment and consumer's purchase intention. Radiat. Phys. Chem. 130, 247-251 (2017).

112. MacRitchie, L. A., Hunter, C. J. \& Strachan, N. J. C. Consumer acceptability of interventions to reduce Campylobacter in the poultry food chain. Food Control 35, 260-266 (2014).

113. King, A. A. \& Baatartogtokh, B. How useful is the theory of disruptive innovation? MIT Sloan Manage. Rev. 57, 77-90 (2015).

114. Hartmann, C., Dohle, S. \& Siegrist, M. Importance of cooking skills for balanced food choices. Appetite 65, 125-131 (2013).

115. Poore, J. \& Nemecek, T. Reducing food's environmental impacts through producers and consumers. Science 360, 987-992 (2018).

116. Cohen, J. Fields of dreams: China bets big on genome editing of crops. Science 365, 422-425 (2019).

\section{Author contributions}

M.S. and C.H. defined the structure of the Review. M.S. wrote the first draft and C.H. provided extensive feedback.

\section{Competing interests}

The authors declare no competing interests.

\section{Additional information}

Correspondence should be addressed to M.S. or C.H.

Reprints and permissions information is available at www.nature.com/reprints.

Publisher's note Springer Nature remains neutral with regard to jurisdictional claims in published maps and institutional affiliations.

(c) Springer Nature Limited 2020 